\title{
Urban water infrastructure asset management - a structured approach in four water utilities
}

\author{
M. A. Cardoso*, M. Santos Silva*, S. T. Coelho*, M. C. Almeida* and D. I. C. Covas** \\ * Laboratório Nacional de Engenharia Civil, Av. do Brasil 101, Portugal \\ (E-mail: macardoso@lnec.pt; mssilva@lnec.pt; stcoelho@lnec.pt; mcalmeida@lnec.pt) \\ ** Instituto Superior Técnico, Av. Rovisco Pais, Portugal \\ (E-mail:didia.covas@civil.ist.utl.pt)
}

\begin{abstract}
Water services are a strategic sector of large social and economic relevance. It is therefore essential that they are managed rationally and efficiently. Advanced water supply and wastewater infrastructure asset management is key in achieving adequate levels of service in the future, particularly with regard to reliable and high quality drinking water supply, prevention of urban flooding, efficient use of natural resources and prevention of pollution.

This paper presents a methodology for supporting the development of urban water infrastructure asset management (IAM), developed during the AWARE-P project as well as an appraisal of its implementation in four water utilities. Both water supply and wastewater systems were considered. Due to the different contexts and features of the utilities, the main concerns vary from case to case; some problems essentially are related to performance, others to risk. Cost is a common deciding factor. The paper describes the procedure applied, focusing on the diversity of drivers, constraints, benefits and outcomes. It also points out the main challenges and the results obtained through the implementation of a structured procedure for supporting urban water IAM.
\end{abstract}

Keywords

Asset management; urban water infrastructure; rehabilitation planning 